International Journal of Environmental Research and

Article

www.mdpi.com/journal/ijerph

\title{
Field Testing of Alternative Cookstove Performance in a Rural Setting of Western India
}

\author{
Veena Muralidharan ${ }^{1, \dagger}$, Thomas E. Sussan ${ }^{2, \dagger}$, Sneha Limaye ${ }^{3, *}$, Kirsten Koehler ${ }^{2}$, \\ D’Ann L. Williams ${ }^{2}$, Ana M. Rule ${ }^{2}$, Sanjay Juvekar ${ }^{1}$, Patrick N. Breysse ${ }^{2}$, Sundeep Salvi ${ }^{3}$ \\ and Shyam Biswal ${ }^{2, *}$
}

1 Vadu Rural Health Program, KEM Hospital Research Centre, Pune 411011, India; E-Mails: muralidharanveena@gmail.com (V.M.); sanjay.juvekar@gmail.com (S.J.)

2 Johns Hopkins Bloomberg School of Public Health, Baltimore, MD 21205, USA; E-Mails: tsussan1@jhu.edu (T.E.S.); kkoehle1@jhu.edu (K.K.); dwilli20@jhu.edu (D.L.W.); arule1@jhu.edu (A.M.R.); pbreyss1@jhu.edu (P.N.B.)

3 Chest Research Foundation, Pune 411014, India; E-Mail: ssalvi@crfindia.com

$\dagger$ These authors contributed equally to this work.

* Authors to whom correspondence should be addressed; E-Mails: snehalimaye@crfindia.com (S.L.); sbiswal@jhu.edu (S.B.); Tel.: +91-20-2703-5361 (S.L.); Fax: +91-20-2703-5371 (S.L.); $+1-410-955-0299$ (S.B.).

Academic Editor: Paul B. Tchounwou

Received: 20 November 2014 / Accepted: 27 January 2015 / Published: 3 February 2015

\begin{abstract}
Nearly three billion people use solid fuels for cooking and heating, which leads to extremely high levels of household air pollution and is a major cause of morbidity and mortality. Many stove manufacturers have developed alternative cookstoves (ACSs) that are aimed at reducing emissions and fuel consumption. Here, we tested a traditional clay chulha cookstove (TCS) and five commercially available ACSs, including both natural draft (Greenway Smart Stove, Envirofit PCS-1) and forced draft stoves (BioLite HomeStove, Philips Woodstove HD4012, and Eco-Chulha XXL), in a test kitchen in a rural village of western India. Compared to the TCS, the ACSs produced significant reductions in particulate matter less than $2.5 \mu \mathrm{m}\left(\mathrm{PM}_{2.5}\right)$ and $\mathrm{CO}$ concentrations (Envirofit: 22\%/16\%, Greenway: 24\%/42\%, BioLite: 40\%/35\%, Philips: 66\%/55\% and Eco-Chulha: 61\%/42\%), which persisted after normalization for fuel consumption or useful energy. $\mathrm{PM}_{2.5}$ and $\mathrm{CO}$
\end{abstract}


concentrations were lower for forced draft stoves than natural draft stoves. Furthermore, the Philips and Eco-Chulha units exhibited higher cooking efficiency than the TCS. Despite significant reductions in concentrations, all ACSs failed to achieve PM2.5 levels that are considered safe by the World Health Organization (ACSs: $277-714 \mu \mathrm{g} / \mathrm{m}^{3}$ or $11-28$ fold higher than the WHO recommendation of $\left.25 \mu \mathrm{g} / \mathrm{m}^{3}\right)$.

Keywords: improved cookstove; biomass; particulate matter; carbon monoxide; wood

\section{Introduction}

Approximately 3 billion people, or nearly half of the world's population, currently use solid fuels such as wood, crop residues, animal dung and coal for cooking and heating. The combustion of such fuels results in exceptionally high levels of household air pollution (HAP), which has been identified as the leading environmental risk factor for cause of death worldwide [1]. Among various sources of HAP, burning of biomass fuels for cooking purposes is most widely recognized as a risk factor for respiratory, cardiovascular, ocular, and neurological diseases [2]. A recent report on the global burden of disease indicated that 3.5 million annual deaths and over 110 million disability-adjusted life years were attributable to HAP, which are primarily due to cardiovascular disease, chronic respiratory diseases, lower respiratory infections and cancer [3,4]. Among young children, exposure to HAP is a major risk factor for respiratory infections and is estimated to kill more than 440,000 children under five years of age per year [3]. There is a disproportionate burden of disease among women and children due to their household roles, causing greater exposure to indoor smoke.

Four main strategies have been employed to improve indoor air quality: (1) design and implementation of alternative cookstoves (ACSs); (2) improved household ventilation; (3) increased use of efficient fuels, and; (4) changes in cooking behaviors. These strategies face numerous economic, engineering, and behavioral barriers for adoption. Previous ACS intervention trials have experienced low rates of adoption, and the benefits of ACS use on health have not been firmly established [5-8]. Therefore, in order to successfully reduce HAP exposure, ACSs need to reduce emissions, improve combustion efficiency, and also be acceptable to the intended community for sustained use.

Laboratory tests of ACS emissions and efficiency frequently give different results than field tests because laboratory tests are conducted under controlled conditions by well-trained personnel $[9,10]$. Whereas in real world conditions, HAP levels are not only affected by emissions from cookstoves, but also by house size and construction, ventilation, fuel factors such as type, size and moisture content, human factors such as loading of wood and tending of fire, ambient air pollution, and weather parameters including temperature, wind direction, humidity, and rainfall. As such, laboratory tests are unlikely to capture the true variability in performance characteristics that are experienced in real world households. Our goal was to test five commercially-available ACSs under real world settings in a representative home in the Pune District of Maharashtra state in India to identify the top performing design before initiating a planned large-scale ACS trial. We recognize that testing cookstoves in a single representative house will not capture all the variability that would be experienced by multiple households in a 
large-scale trial, however, this study was conducted in a typical household and recapitulates many of the real world conditions that will be experienced by users in this community.

\section{Materials and Methods}

\subsection{Study Design}

We conducted the study in March 2014 in a village included in the Vadu Rural Health Program (VRHP) located in the Pune district of Maharashtra state, in Western India. Our test kitchen was representative of a typical rural dwelling in the study area. The walls of the test kitchen were made of bricks and cement, the roofing material was made of asbestos sheets without any eave spaces, and the floor consisted of mud coated with cow dung. The kitchen contained one window and one door to the outside, which were open during all tests. The dimensions of the kitchen were $2.6 \mathrm{~m} \times 2 \mathrm{~m} \times 1.8 \mathrm{~m}$. The window dimensions were $0.6 \mathrm{~m} \times 0.6 \mathrm{~m}$ and the door was $1.9 \mathrm{~m} \times 0.6 \mathrm{~m}$. The kitchen was a separate room from the sleeping area separated with a door opening into the sleeping room. We tested the traditional clay chulha cookstove (TCS) that was fixed to the ground and five commercially available ACSs, which included both natural draft stoves (Greenway Smart Stove-Greenway Appliances, Mumbai, Maharashtra, India; Envirofit PCS-1—Envirofit International Inc., Fort Collins, CO, USA) and forced draft stoves (BioLite HomeStove-Biolite Inc., New York, NY, USA; Philips Wood Stove HD4012 - Philips Research, Eindhoven, The Netherlands; and Eco Chulha XXL-Alpha Renewable Energy Pvt. Ltd., Anand, Gujarat, India). The six cookstoves (one traditional and five ACSs) were used sequentially to heat 2 liters of water to boil for a total duration of $1 \mathrm{~h}$ each day, followed by a $20 \mathrm{~min}$ washout period, sufficient for pollution levels in the home to decay to ambient conditions before starting the next cookstove test. The order of the six cookstoves was staggered each day for a total of 12 days $\left(N=72\right.$ trials). We measured indoor particulate matter less than $2.5 \mu \mathrm{m}\left(\mathrm{PM}_{2.5}\right)$ and carbon monoxide (CO) concentrations, fuel consumption, time to boil water and volume of water boiled, while controlling for several factors, including fuel type, fuel weight, size, and dryness. We used acacia wood (commonly used as firewood in study area) that was collected at the same time and stored in a dry place until use, and the stoves were operated by a single user. Additionally standard amounts of cow dung (200 g) and kerosene $(20 \mathrm{~mL})$ were used for igniting the wood, as typical for this region. All ACSs were operated as recommended by the manufacturers' guidelines, and fuel was loaded at slow and steady rates in order to ensure that the cookstoves were not overloaded, did not produce excessive emissions, and did not waste fuel.

\subsection{Cookstove Performance}

A battery operated, data-logging, real-time aerosol monitor (pDR-1200, Thermo Scientific, Franklin, MA, USA) equipped with a cyclone inlet was used to measure concentrations of $\mathrm{PM}_{2.5}$ every minute at a flow rate of $4 \mathrm{~L} \cdot \mathrm{min}^{-1}$ using a BGI 400S vacuum pump (BGI Inc., Waltham, MA, USA). Real-time $\mathrm{CO}$ was measured at a sampling rate of once per minute using an EasyLog Carbon Monoxide data logger (EL-USB-CO, Lascar Electronics, Erie, PA, USA). Both $\mathrm{PM}_{2.5}$ and $\mathrm{CO}$ instruments were placed two meters away from the cookstoves and at a height of $1.5 \mathrm{~m}$. Baseline concentrations of $\mathrm{PM}_{2.5}$ and $\mathrm{CO}$ were measured before testing with the cookstoves. 
In order to convert pDR readings to gravimetric equivalent results, we collected co-located $\mathrm{PM}_{2.5}$ filter samples in a subset of trials. Filters were pre-weighed and post-weighed in a temperature and humidity controlled weighing room at Johns Hopkins University using U.S. EPA standard reference methods [11]. Temperature and humidity were assessed during each trial using a temperature and relative humidity data logger (HOBO, Onset Computer Corporation, Bourne, MA, USA). Average temperature and relative humidity were $37{ }^{\circ} \mathrm{C}$ and $37 \%$, respectively. Nephelometer readings were gravimetrically calibrated and adjusted for relative humidity, as previously described [12].

Concentrations of $\mathrm{PM}_{2.5}$ and $\mathrm{CO}$ were normalized to either fuel consumption or useful energy. Useful energy is the sum of sensible heat and latent heat, which were calculated using the equations:

$$
\text { Q Sensible }=M_{w} \cdot C_{p w} \cdot\left(T_{b}-T_{i}\right)
$$

where $\mathrm{M}_{\mathrm{w}}$ is the initial mass of water $(\mathrm{kg})$ that was heated from the initial temperature $\left(T_{i}\right)$ to boiling $\left(T_{b}\right) . C_{p w}$ is the specific heat of water $\left(\mathrm{kJ} / \mathrm{kg} \cdot{ }^{\circ} \mathrm{C}\right)$.

$$
\mathrm{Q} \text { Latent }=M_{w e} \cdot L_{v}
$$

where $M_{w e}$ is the mass of water evaporated $(\mathrm{kg})$ and $L_{v}$ is the latent heat of vaporization $(\mathrm{kJ} / \mathrm{kg})$.

\subsection{Cooking Efficiency}

Cooking efficiency is defined as the ratio of energy used to heat the water versus the energy content of the fuel consumed [13]. A known quantity (2 liters) of water was heated for a period of one hour. The temperature of the water was continuously monitored. In order to calculate the efficiency of the stove, the initial temperature of water, the volume of water remaining after the one-hour test, and the remaining weight of wood at end of each cooking session was measured. The stove efficiency $(\eta)$ is the useful energy delivered divided by the fuel energy, which was calculated using the formula:

$$
\eta=\left(M_{w} \cdot C_{p w} \cdot\left(T_{b}-T_{i}\right)+M_{w e} \cdot L_{v}\right) / M_{f} \cdot H_{f}
$$

where $M_{w}$ is the initial mass of water in the cooking vessel $(\mathrm{g}), C_{p w}$ is the specific heat of water $\left(\mathrm{J} / \mathrm{g} \cdot{ }^{\circ} \mathrm{C}\right)$, $T_{b}$ is the temperature of boiling water $\left({ }^{\circ} \mathrm{C}\right), T_{i}$ is the initial temperature of water $\left({ }^{\circ} \mathrm{C}\right), M_{w e}$ is the mass of water evaporated $(\mathrm{g}), L v$, is the latent heat of vaporization $(\mathrm{J} / \mathrm{g}), M_{f}$ is the net mass of fuel used $(\mathrm{g})$, and $H_{f}$ is the calorific value of fuel $\left(19.7 \times 10^{3} \mathrm{~J} / \mathrm{g}\right.$ ) (higher heating value). The first term in the numerator represents the energy required to heat the water from the initial temperature to boiling, the second term in the numerator represents the energy required to boil off the evaporated volume of water, and the denominator represents the energy content of the spent fuel.

\subsection{Statistical Analyses}

The data were analyzed using SAS (version 9.4, SAS Institute Inc., Cary, NC, USA). PM2.5 and CO concentration data were log-transformed prior to statistical analysis. A linear mixed model was used to assess statistical differences in $\mathrm{PM}_{2.5}$ mass and $\mathrm{CO}$ concentrations between the ACSs and the TCS accounting for repeated measures. The stove concentration estimates, transformed back to the linear scale, were used to estimate the percentage change in $\mathrm{PM}_{2.5}$ and $\mathrm{CO}$ concentrations. Calculated $95 \%$ confidence intervals were used to determine if an ACS was significantly different than the TCS. Differences between TCS and ACSs were also assessed for time to boil, fuel consumed in $1 \mathrm{~h}$, and stove efficiency. 


\subsection{Ethical Considerations}

The study was reviewed and approved by KEMHRC, CRF and Johns Hopkins Institutional Review Boards. Although not a clinical trial, all ethical procedures of community based studies and good clinical practices were strictly followed in the execution of the study.

\section{Results}

\subsection{Concentrations of $P M_{2.5}$ and $C O$}

Summary statistics for average $\mathrm{PM}_{2.5}$ and $\mathrm{CO}$ concentrations over the 12 cooking events are summarized in Table 1. The median concentrations of $\mathrm{PM}_{2.5}$ and $\mathrm{CO}$ that were generated by cooking with the TCS were $916 \mu \mathrm{g} / \mathrm{m}^{3}$ and $16.0 \mathrm{ppm}$, respectively. Reductions in median PM2.5 (Figure 1A) and $\mathrm{CO}$ (Figure 1B) concentrations were observed for all ACSs compared to the TCS. Mean PM2.5 concentrations (all tests combined) were reduced by 22\% (Envirofit PCS-1), 24\% (Greenway), 40\% (BioLite), 66\% (Philips), and 61\% (Eco-Chulha). PM2.5 concentrations were significantly lower for all ACSs compared to the TCS. Mean CO concentrations were reduced by $16 \%$ (Envirofit PCS-1), 42\% (Greenway), 35\% (BioLite), 55\% (Philips), and 42\% (Eco-Chulha) compared to the TCS. A statistically significant reduction in CO concentration was observed for all ACSs in comparison to TCS, except for Envirofit. In general, forced draft cookstoves outperformed the natural draft cookstoves.

Table 1. Pollutant concentrations from traditional and alternative cookstove use in a real-world test kitchen.

\begin{tabular}{cccccc|ccccc}
\hline \multirow{2}{*}{ Cookstove } & \multicolumn{3}{c}{$\mathbf{P M}_{\mathbf{2 . 5}}$ Mass Concentration $\left(\boldsymbol{\mu g} / \mathbf{m}^{\mathbf{3}}\right)$} & \multicolumn{5}{c}{ CO Concentration (ppm) } \\
\cline { 2 - 11 } & $\mathbf{M i n}^{*}$ & $\mathbf{2 5 \%}$ & $\mathbf{5 0 \%}$ & $\mathbf{7 5 \%}$ & $\mathbf{M a x}{ }^{*}$ & Min $^{*}$ & $\mathbf{2 5 \%}$ & $\mathbf{5 0 \%}$ & $\mathbf{7 5 \%}$ & Max $^{*}$ \\
\hline TCS & 619 & 757 & 916 & 1082 & 1156 & 10.0 & 14.3 & 16.0 & 18.6 & 22.4 \\
Envirofit & 524 & 656 & 714 & 763 & 871 & 10.9 & 11.8 & 12.7 & 14.5 & 16.1 \\
Greenway & 388 & 561 & 687 & 804 & 1177 & 6.6 & 9.4 & 11.3 & 12.5 & 18.8 \\
BioLite & 367 & 470 & 555 & 651 & 827 & 7.3 & 8.6 & 9.6 & 11.0 & 14.3 \\
Philips & 198 & 266 & 277 & 284 & 305 & 5.1 & 6.0 & 7.5 & 7.8 & 10.4 \\
Eco-Chulha & 209 & 263 & 314 & 489 & 555 & 7.0 & 8.4 & 9.1 & 10.0 & 16.3 \\
\hline
\end{tabular}

* Each cookstove was tested in 12 separate trials, and the minimum and maximum concentrations represent the trials with the lowest and highest average concentrations over the $1 \mathrm{~h}$ test.

Generally, $\mathrm{CO}$ concentrations are easier and cheaper to measure than $\mathrm{PM}_{2.5}$ concentrations. As such, $\mathrm{CO}$ is often used as a proxy for cookstove emissions $[14,15]$. Our data demonstrate that $\mathrm{CO}$ and $\mathrm{PM}_{2.5}$ are strongly correlated when the data are combined across all cookstoves $(\rho=0.82 ; p<0.0001)$ (Figure 1C). However, the correlation varied considerably between cookstoves, both in terms of linear regression slope and Spearman's rank correlation coefficient. The Philips ACS showed no relationship between $\mathrm{PM}_{2.5}$ and $\mathrm{CO}$ (95\% confidence intervals of the linear regression slope included zero). Thus, ACS implementation studies that measure only one pollutant may not capture the changes in all pollutants. 

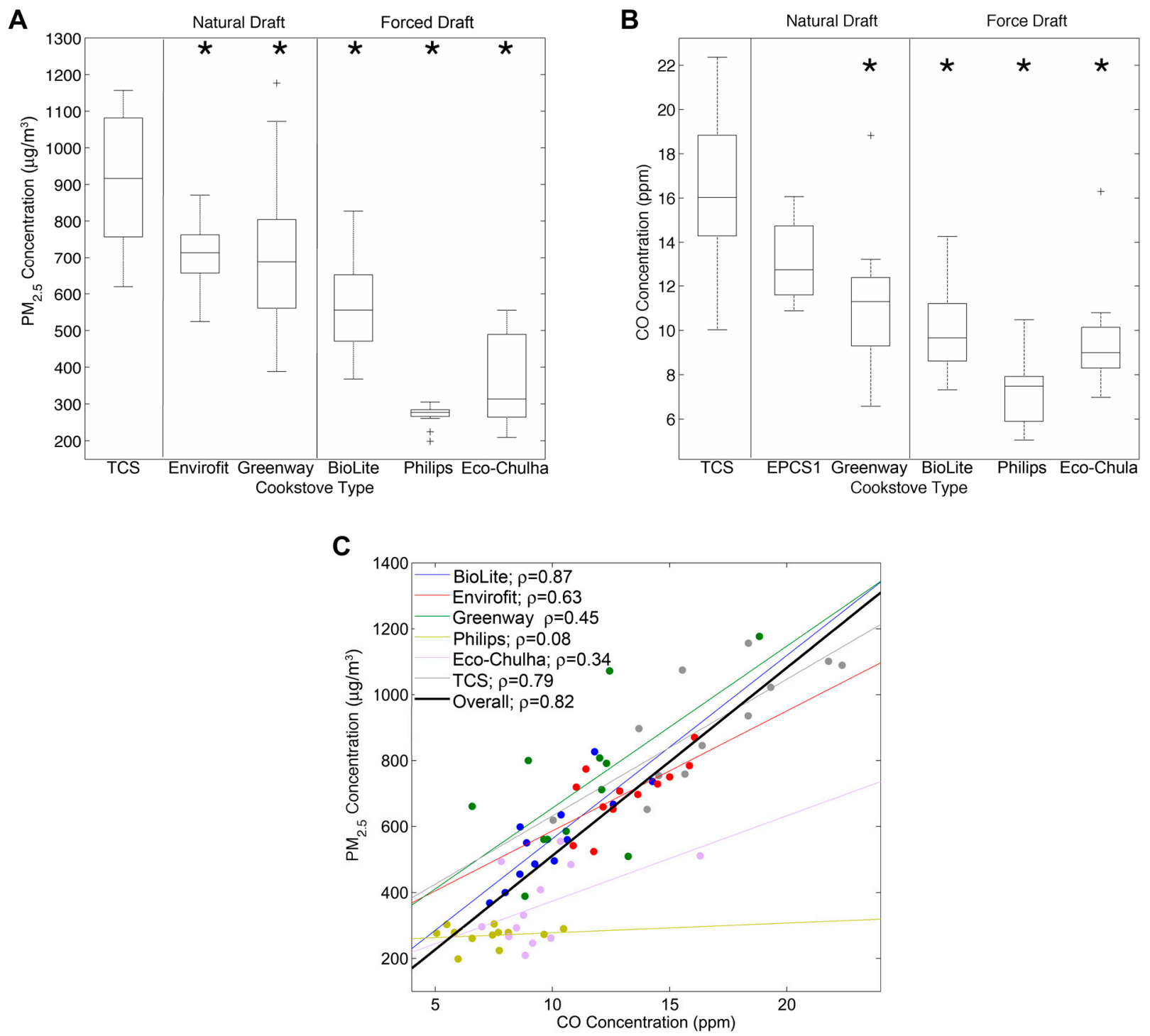

Figure 1. $\mathrm{PM}_{2.5}$ and $\mathrm{CO}$ concentrations generated from cookstoves. (A) Box plots depicting $\mathrm{PM}_{2.5}$ concentrations for the traditional cookstove (TCS), natural draft ACSs (Envirofit and Greenway), and forced draft ACSs (BioLite, Philips, and Eco-Chulha). Box plots are calculated from the average $\mathrm{PM}_{2.5}$ concentrations during each $1 \mathrm{~h}$ cooking event $(n=12$ per stove). (B) $\mathrm{CO}$ concentrations for the same cooking events as in (A). (C) Correlations between $\mathrm{PM}_{2.5}$ and $\mathrm{CO}$ concentrations were expressed as the Spearman's rank correlation coefficient and linear regression for each cookstove. ${ }^{*} p<0.02$.

\subsection{Cooking Efficiency and Cooking Characteristics}

Measurements of fuel consumption revealed that ACSs used slightly less wood during the $1 \mathrm{~h}$ cooking events than the TCS (Figure 2). To determine whether the reduced pollutant concentrations were due to reduced fuel consumption, we normalized the $\mathrm{PM}_{2.5}$ and $\mathrm{CO}$ concentrations by the mass of fuel consumed ( $\mu \mathrm{g} / \mathrm{m}^{3} / \mathrm{g}$ and $\mathrm{ppm} / \mathrm{g}$ for $\mathrm{PM}_{2.5}$ and CO, respectively). Compared to the TCS, normalized $\mathrm{PM}_{2.5}$ concentrations were significantly reduced in four of the five ACSs tested (Figure 3A, marginally significant for the Greenway stove, $p=0.056$ ). Normalized CO concentrations were significantly reduced in all five ACSs tested (Figure 3B). For both $\mathrm{PM}_{2.5}$ and CO, normalized concentrations were 
lower in the forced draft stoves than in the natural draft stoves. Thus, even after normalizing for fuel consumption, ACSs still result in lower HAP than the TCS.

We also normalized pollutant concentrations to useful heat energy that was delivered to the pot, which is the energy absorbed by the water. After normalization for useful energy delivered. concentrations of $\mathrm{PM}_{2.5}$ were significantly reduced for the forced draft stoves (BioLite, Philips, and Eco-Chulha) compared to the TCS (Figure 3C), while normalized CO concentrations were significantly reduced for the Greenway, BioLite, Philips, and Eco-Chulha cookstoves (Figure 3D). Thus, the reduced pollutant concentrations were partially due to reduced useful heat energy, particularly for the natural draft stoves.

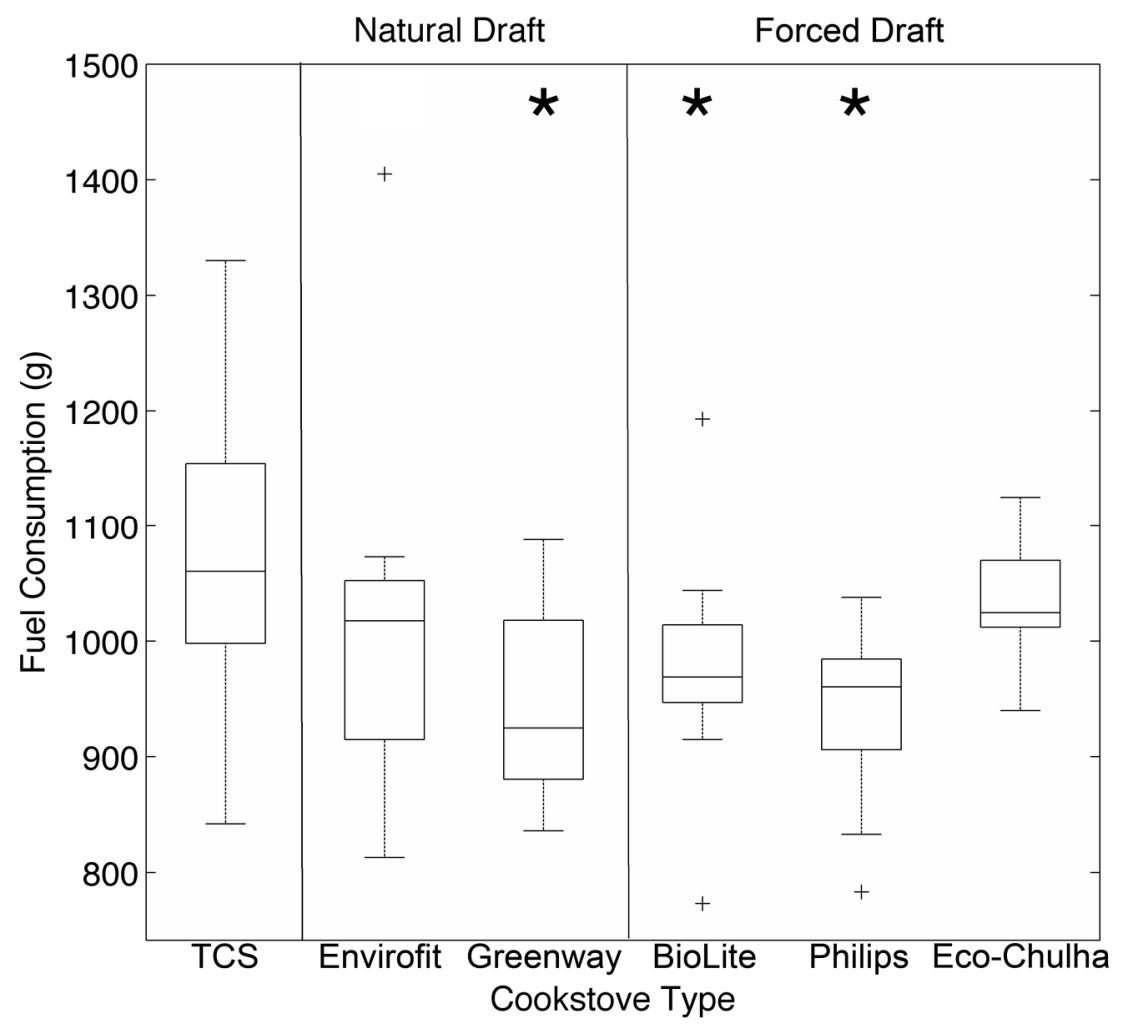

Figure 2. Fuel consumption was determined for each cooking event. The BioLite $(p=0.03)$, Greenway $(p<0.01)$ and Phillips $(p<0.01)$ stoves consumed significantly less fuel than the TCS. ${ }^{*} p<0.03$.

We determined the time for each cook stove to raise the temperature of $2 \mathrm{~L}$ of water from a nominal $44{ }^{\circ} \mathrm{C}$ to boiling. The time required to boil water did not differ between the TCS and the natural draft cookstoves (Figure 4A). Among the forced draft cookstoves, Philips and Eco-Chulha stoves required significantly less time to boil water than the TCS $(p<0.01)$, but the BioLite stove required significantly more time to boil the water $(p<0.01)$. Cooking efficiency (Equation (3)) is another important determinant that was used to compare ACS performance because it has a major influence on acceptance and adoption [16]. The average cooking efficiency of the TCS was 11.6\% (Figure 4B), which is similar to previous reports of efficiency for TCS [13]. Cooking efficiency of the Philips (25.3\%) and Eco-Chulha (16.9\%) were significantly higher than the TCS, but the Envirofit (11.7\%) and Greenway (11.9\%) exhibited similar efficiency as observed for the TCS. The BioLite stove was the least efficient cookstove 
$(10.3 \%$, marginally significantly lower $p=0.052)$. Thus, while all ACSs reduced pollutant concentrations, they had variable effects on cooking efficiency.
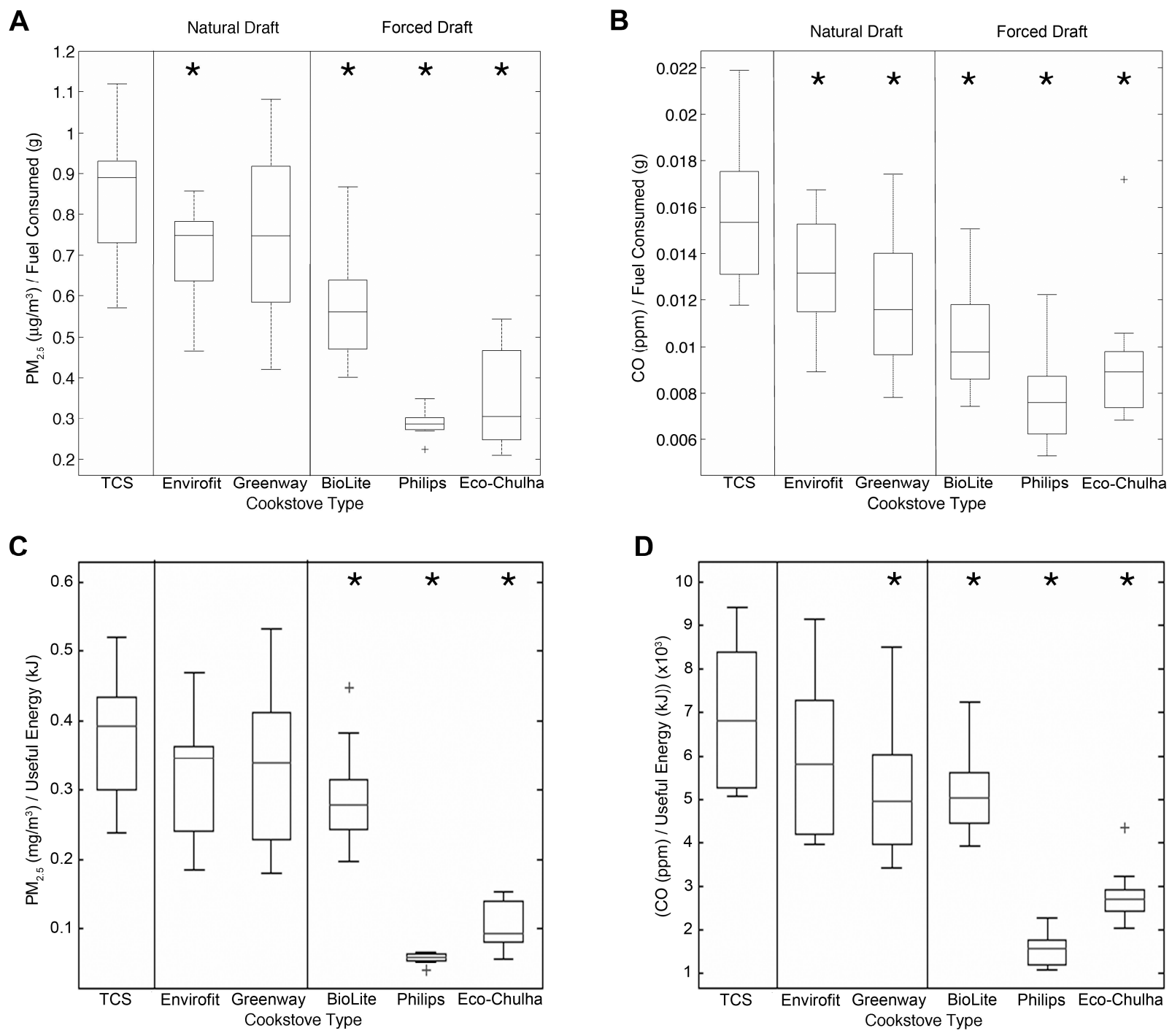

Figure 3. Pollutant concentrations after normalization for fuel consumption or useful energy. (A) $\mathrm{PM}_{2.5}$ concentrations were significantly reduced for the BioLite, Envirofit, Phillips, and Eco-Chulha stoves $(p<0.001)$ after normalization for fuel consumption. Normalized $\mathrm{PM}_{2.5}$ concentration reduction for the Greenway stove was marginally significant ( $p=0.056)$. (B) $\mathrm{CO}$ concentrations were significantly reduced for all ACSs after normalization for fuel consumption * $p<0.03$. (C) $\mathrm{PM}_{2.5}$ concentrations were significantly reduced for the BioLite, Phillips, and Eco-Chulha stoves after normalization for useful heat energy. (D) CO concentrations were significantly reduced for Greenway, BioLite, Philips, and Eco-Chulha ACSs after normalization for useful energy delivered. 
A

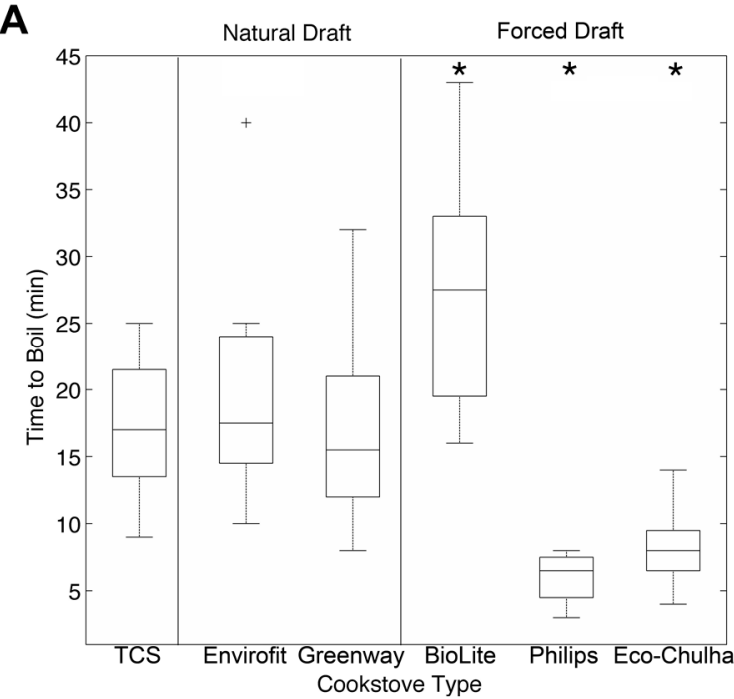

B

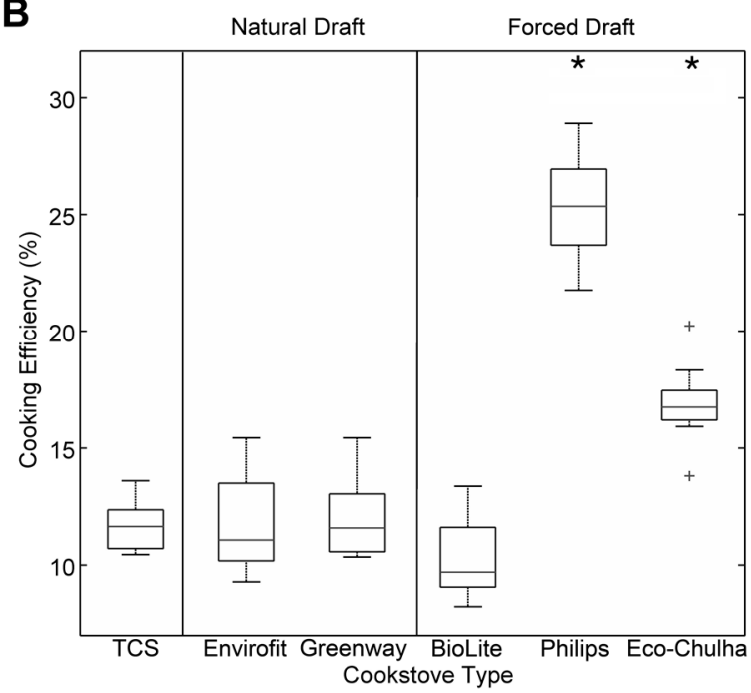

Figure 4. (A) Boxplots depicting time to boil $2 \mathrm{~L}$ of water, in minutes. The BioLite stove required significantly more time than the TCS $(p=0.001)$; the Greenway and Phillips $(p<0.01)$ required significantly less time to boil water than the TCS. (B) Cooking efficiency was calculated using Equation 3. Cooking efficiency was significantly higher for the Philips and Eco-Chulha stoves $(p<0.01)$; cooking efficiency was marginally significantly lower for the BioLite $(p=0.052) .{ }^{*} p<0.01$.

\subsection{Cooking Efficiency vs. Pollutant Concentrations}

The ideal ACS should incorporate high combustion efficiency to produce low emissions and effectively transfer this energy to the pot to provide heat. We plotted average $\mathrm{PM}_{2.5}$ or CO concentrations $v s$. average cooking efficiency for each cookstove (Figure 5). The concentrations were reduced among the forced draft stoves compared to the TCS and natural draft stoves, but the three forced draft stoves varied widely in cooking efficiency (Figure 5). The Philips ACS showed the best combination of low pollutant concentrations and high cooking efficiency.
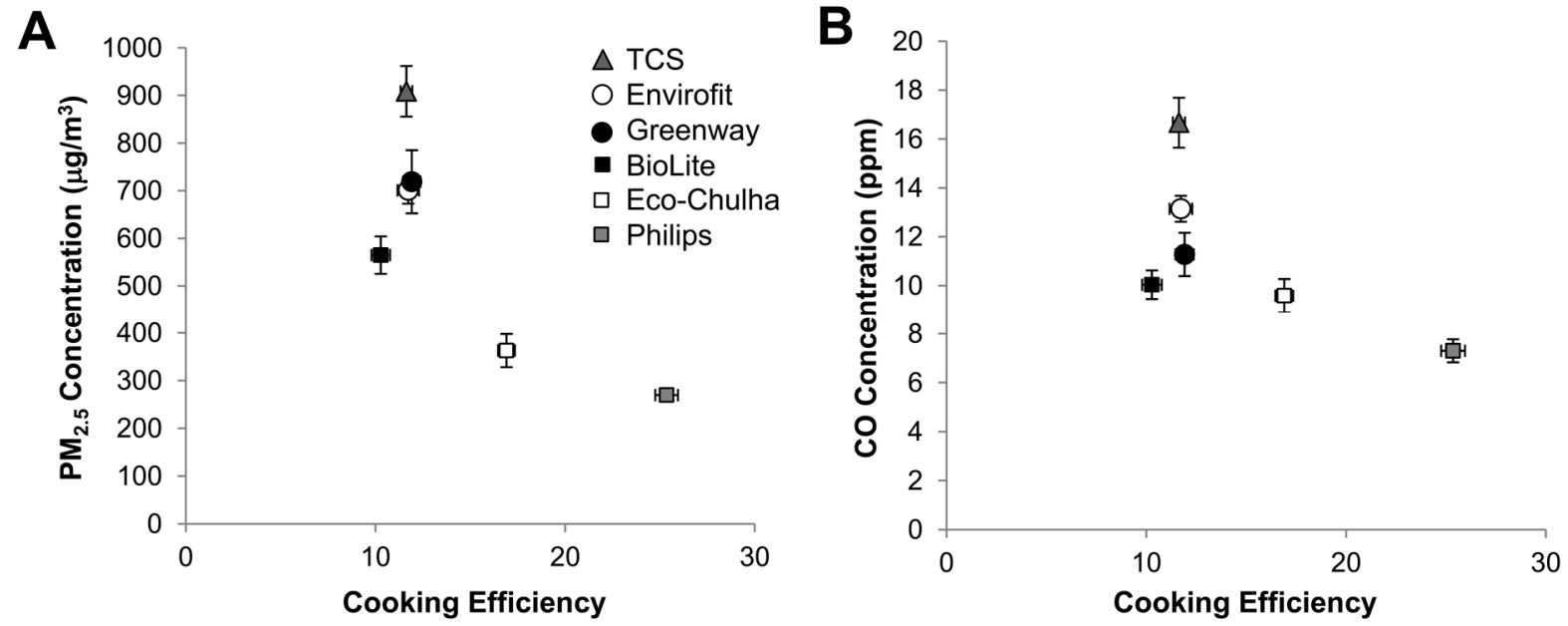

Figure 5. Cooking efficiencies were compared to $\mathrm{PM}_{2.5}$ concentrations (A) and $\mathrm{CO}$ concentrations (B) Data is presented as mean \pm SEM. 


\section{Discussion}

The results of this study indicate that forced draft stoves (BioLite, Philips, Eco-Chulha) reduce mean $\mathrm{PM}_{2.5}$ concentrations by at least $40 \%$ and $\mathrm{CO}$ concentrations by at least $35 \%$, compared to the TCS. Among the three forced draft stoves that we tested, the Philips Woodstove exhibited the strongest reduction in $\mathrm{PM}_{2.5}(66 \%)$ and $\mathrm{CO}(55 \%)$ concentrations. Although natural draft stoves (Envirofit and Greenway) did not reduce concentrations to the same extent as the forced draft stoves did, they still resulted in substantial reductions in $\mathrm{PM}_{2.5}$ and $\mathrm{CO}$ concentrations compared to the TCS. This difference between forced draft and natural draft stoves is to be expected because forced draft stoves include a fan that delivers air directly to the fire to improve combustion. The current study is consistent with a previous comparison of pollutant levels in various commercially available cookstoves, which showed that natural draft and forced draft ACSs reduce black carbon content by $39 \%$ and $70 \%$, respectively [17], while the Philips forced draft ACS has been shown to reduce emissions by $90 \%$ under laboratory conditions [18].

The World Health Organization has set guidelines for concentrations of $\mathrm{PM}_{2.5}$ and $\mathrm{CO}$ that have significant impacts on health [19]. It should be noted that the concentrations of PM 2.5 measured in this study while cooking with the ACSs were well above the acceptable limits set by the WHO (i.e., $25 \mu \mathrm{g} / \mathrm{m}^{3}$ 24-h mean). The CO levels measured in this study were relatively low, and all cookstoves, including the TCS, were below the WHO recommended level of $26 \mathrm{ppm}$ (1-h mean). However, typical cooking times in India are 3-7 h per day, and only the Philips stove was below the recommended 8-h mean of 9 ppm. Therefore, despite significant reductions in $\mathrm{PM}_{2.5}$ concentrations, all of the ACSs failed to achieve $\mathrm{PM}_{2.5}$ levels that may be considered safe. However, potential improvements to the health of women and children resulting from the reduced pollutant concentrations observed here are unclear. Previous studies indicate that use of ACSs can have beneficial effects on health $[6,7,20,21]$ although the benefits have generally been mild. More substantial benefits may require greater reductions in emissions or extended duration of time. For example, a recent prospective cohort study in China demonstrated that use of alternative fuels during the 9-year follow-up resulted in significant improvements in lung function [22]. More research is needed to assess the potential health benefits of ACS use.

In recent years several ACS intervention programs have been conducted, with the goal of reducing exposure to HAP and improving health [5-7,23]. Similar to our study, several studies [24,25] have demonstrated that implementation of ACSs can reduce the concentrations of $\mathrm{PM}_{2.5}$ and $\mathrm{CO}$ in households; however, the exposure-response relationship between pollutant concentrations and various aspects of lung health have not been determined. One of the largest cookstove intervention trials to date utilized a plancha stove (a traditional griddle with a hot plate heated from below) with a chimney that reduced $\mathrm{PM}_{2.5}$ exposures by approximately $60 \%$, and improved systolic blood pressure, rate of severe pneumonia, cardiac ischemia, birth weight, and respiratory symptoms over a period of 18 months [7,15,26-28]. However, these health benefits were generally mild, were often insignificant statistically, and many of the primary outcomes (i.e., pneumonia diagnoses, heart rate variability, and lung function) did not change. Hence, in order to produce substantial improvements in health, exposure levels need to be further reduced [29]. The $\mathrm{PM}_{2.5}$ and $\mathrm{CO}$ levels achieved in our current study were comparable to these previous studies. Therefore, it is not clear whether implementation of any of the ACSs tested here will substantially improve health. Burning of unprocessed biomass is an inefficient process, and it is unclear whether any biomass cookstove design could achieve acceptable emissions. 
More research is needed to determine whether current cookstove replacement intervention trials can reduce pollutant concentrations to an extent that can benefit health. The Global Alliance for Clean Cookstoves is conducting a large-scale multi-faceted effort with the stated goal of converting 100 million households to efficient cookstoves by 2020, despite limited information to determine whether adoption of efficient cookstoves will reduce emissions to an extent that will improve health. While efforts are currently underway to develop internationally recognized standards for ACS, it is important to distinguish ratings based on controlled laboratory settings and assessments conducted under normal field conditions.

Although several national and international programs are working towards the implementation and dissemination of ACSs in developing countries, acceptance and adoption rates remain low $[5,6]$. Although reduction in emissions is an important component of stove performance, other factors, such as fuel efficiency and heat output also influence stove adoption and acceptability. In fact, a recent survey conducted in India revealed that the primary criterion for a "good" stove was fuel efficiency, followed by smoke emissions [30]. All ACSs exhibited at least a slight decrease in fuel consumption during the 1 $\mathrm{h}$ cooking events, compared to the TCS, but the time required to boil water and cooking efficiency varied considerably for each stove. For these parameters, the natural draft stoves were comparable to the TCS, but the Philips and Eco-Chulha stoves were superior to the TCS. The BioLite stove used significantly less fuel than the TCS, but also generated less heat. Although forced draft stoves tend to perform better than natural draft stoves, they require electricity to power a fan, may require the user to turn the fan on or control fan speed, and are typically more expensive than natural draft stoves. Affordability, ease of use, and maintenance are also significant determinants of stove adoption, and natural draft stoves have an advantage over forced draft stoves in this regard. Some manufacturers of forced draft stoves have attempted to reduce the dependence on an external electrical source through incorporation of rechargeable batteries (Philips) or thermoelectric conduction systems (BioLite), but the batteries require proper charging and the BioLite thermoelectric conduction system will only power the fan after the stove has been in use for several minutes.

The primary goal of our study was to assess several ACSs under real world conditions. Our study controlled for many parameters, including lighting and cooking practices, fuel, and household structure, but allowed other factors, such as weather conditions, to vary. Additionally, we only operated the cookstoves under relatively high power, which may not be representative of pollutant concentrations generated when operating at lower power. Thus, cookstove intervention trials are likely to encounter greater variability in emissions and efficiency than what we have reported through this study.

\section{Conclusions}

$\mathrm{PM}_{2.5}$ and $\mathrm{CO}$ concentrations measured for ACSs in a field test kitchen were comparatively lower than the concentrations from TCS. Forced draft stoves produced the lowest concentrations. Despite significant reduction in concentrations, the tested ACSs were unable to achieve levels of $\mathrm{PM}_{2.5}$ within the permissible limits set by the WHO, as overall, $\mathrm{PM}_{2.5}$ concentrations from the ACSs were still 11-28 fold higher than the level recommended by the WHO. This conforms to previous findings [24,31] that solid-fuel ACSs without effective chimneys and adequate ventilation are unable to reduce indoor air pollution to levels that could be considered safe. This also triggers a need to think beyond ACSs for achieving safe limits 
of household air pollutants. More studies are urgently needed to address gaps in knowledge with regard to HAP exposure, health responses, and ACS acceptance. Our current study provides evidence for feasibility of conducting a community-based intervention trial using ACSs. It also indicates that large scale community based field trials involving intense follow up are needed.

\section{Acknowledgements}

The authors would like to acknowledge the field research assistants and villagers from Vadu who provided active support in conducting this study. We would like to acknowledge the families of Jalindhar Radhaghuji Raut and Gangaram Bajirao Argade for opening up their households and providing their kitchens for conducting this study. Furthermore, we would like to thank Pallavi Lele, Rutuja Patil, Ankita Shrivastava, Dhiraj Agarwal, Vijay Gaikwad, Vaibhav Raut, Santosh Shivale, and Amol Bhosale from VRHP for providing us their support in this study. Lastly, we would like to acknowledge all the ACS manufacturers for providing us the cookstoves. This work was supported by a joint center funded by the Indo-US Science and Technology Forum (Shyam Biswal, Sneha Limaye, Patrick Breysse, Thomas E. Sussan); by Fogarty grant R03 TW008741 (Shyam Biswal and Sneha Limaye); and by Johns Hopkins Center for Global Health Faculty Pilot Grant (Thomas E. Sussan). Thomas E. Sussan is partially supported by a Young Clinical Scientist Award from FAMRI.

\section{Author Contributions}

Sneha Limaye, Sundeep Salvi, Sanjay Juveka, Patrick Breysse, Thomas E. Sussan and Shyam Biswal conceived and designed the experiments; Veena Muralidharan, D'Ann L. Williams and Ana M. Rule performed the experiments; Kirsten Koehler, Thomas E. Sussan, Veena Muralidharan and Patrick N. Breysse analyzed the data; Thomas E. Sussan, Veena Muralidharan and Kirsten Koehler wrote the paper.

\section{Conflicts of Interest}

The authors declare no conflict of interest.

\section{References}

1. Martin, W.J., 2nd; Glass, R.I.; Balbus, J.M.; Collins, F.S. Public health: A major environmental cause of death. Science 2011, 334, 180-181.

2. Fullerton, D.G.; Bruce, N.; Gordon, S.B. Indoor air pollution from biomass fuel smoke is a major health concern in the developing world. Trans. R. Soc. Trop. Med. Hyg. 2008, 102, 843-851.

3. Lim, S.S.; Vos, T.; Flaxman, A.D.; Danaei, G.; Shibuya, K.; Adair-Rohani, H.; Amann, M.; Anderson, H.R.; Andrews, K.G.; Aryee, M.; et al. A comparative risk assessment of burden of disease and injury attributable to 67 risk factors and risk factor clusters in 21 regions, 1990-2010: A systematic analysis for the global burden of disease study 2010. Lancet 2012, 380, 2224-2260. 
4. Smith, K.R.; Bruce, N.; Balakrishnan, K.; Adair-Rohani, H.; Balmes, J.; Chafe, Z.; Dherani, M.; Hosgood, H.D.; Mehta, S.; Pope, D.; et al. Millions dead: How do we know and what does it mean? Methods used in the comparative risk assessment of household air pollution. Annu. Rev. Public Health 2014, 35, 185-206.

5. Duflo, E.; Greenstone, M.; Hanna, R. Up in Smoke: The Influence of Household Behavior on the Long-Run Impact of Improved Cooking Stoves; Harvard Environmental Economics Program: Cambridge, MA, USA, 2012.

6. Romieu, I.; Riojas-Rodriguez, H.; Marron-Mares, A.T.; Schilmann, A.; Perez-Padilla, R.; Masera, O. Improved biomass stove intervention in rural mexico: Impact on the respiratory health of women. Am. J. Respir. Crit. Care Med. 2009, 180, 649-656.

7. Smith, K.R.; McCracken, J.P.; Weber, M.W.; Hubbard, A.; Jenny, A.; Thompson, L.M.; Balmes, J.; Diaz, A.; Arana, B.; Bruce, N. Effect of reduction in household air pollution on childhood pneumonia in guatemala (respire): A randomised controlled trial. Lancet 2011, 378, 1717-1726.

8. Semple, S.; Apsley, A.; Wushishi, A.; Smith, J. Commentary: Switching to biogas-What effect could it have on indoor air quality and human health? Biomass Bioenergy 2014, 70, 125-129.

9. Chen, Y.; Roden, C.A.; Bond, T.C. Characterizing biofuel combustion with patterns of real-time emission data (parted). Environ. Sci. Technol. 2012, 46, 6110-6117.

10. Roden, C.A.; Bond, T.C.; Conway, S.; Pinel, A.B.O.; MacCarty, N.; Still, D. Laboratory and field investigations of particulate and carbon monoxide emissions from traditional and improved cookstoves. Atmos. Environ. 2009, 43, 1170-1181.

11. Environmental Protection Agency. National Ambient Air Quality Standards for Particulate Matter; Final Rule; Environmental Protection Agency: Washington, DC, USA, 40 CFR Part 50, Appendix L: 1997.

12. Soneja, S.; Chen, C.; Tielsch, J.M.; Katz, J.; Zeger, S.L.; Checkley, W.; Curriero, F.C.; Breysse, P.N. Humidity and gravimetric equivalency adjustments for nephelometer-based particulate matter measurements of emissions from solid biomass fuel use in cookstoves. Int. J. Environ. Res. Public Health 2014, 11, 6400-6416.

13. Bhattacharya, S.C.; Albina, D.O.; Salam, P.A. Emission factors of wood and charcoal-fired cookstoves. Biomass Bioenergy 2002, 23, 453-469.

14. Naeher, L.P.; Smith, K.R.; Leaderer, B.P.; Neufeld, L.; Mage, D.T. Carbon monoxide as a tracer for assessing exposures to particulate matter in wood and gas cookstove households of highland guatemala. Environ. Sci. Technol. 2001, 35, 575-581.

15. Smith-Sivertsen, T.; Diaz, E.; Pope, D.; Lie, R.T.; Diaz, A.; McCracken, J.; Bakke, P.; Arana, B.; Smith, K.R.; Bruce, N. Effect of reducing indoor air pollution on women's respiratory symptoms and lung function: The respire randomized trial, guatemala. Am. J. Epidemiol. 2009, 170, 211-220.

16. Shankar, A.; Johnson, M.; Kay, E.; Pannu, R.; Beltramo, T.; Derby, E.; Harrell, S.; Davis, C.; Petach, H. Maximizing the benefits of improved cookstoves: Moving from acquisition to correct and consistent use. Glob. Health Sci. Pract. 2014, 2, 268-274.

17. Kar, A.; Rehman, I.H.; Burney, J.; Puppala, S.P.; Suresh, R.; Singh, L.; Singh, V.K.; Ahmed, T.; Ramanathan, N.; Ramanathan, V. Real-time assessment of black carbon pollution in indian households due to traditional and improved biomass cookstoves. Environ. Sci. Technol. 2012, 46, 2993-3000. 
18. Jetter, J.; Zhao, Y.; Smith, K.R.; Khan, B.; Yelverton, T.; Decarlo, P.; Hays, M.D. Pollutant emissions and energy efficiency under controlled conditions for household biomass cookstoves and implications for metrics useful in setting international test standards. Environ. Sci. Technol. 2012, 46, 10827-10834.

19. Krzyzanowski, M.; Cohen, A. Update of who air quality guidelines. Air Qual. Atmos. Health 2008, $1,7-13$.

20. Alexander, D.; Linnes, J.C.; Bolton, S.; Larson, T. Ventilated cookstoves associated with improvements in respiratory health-related quality of life in rural bolivia. J. Public Health (Oxf.) 2013, 36, 460-466.

21. Guarnieri, M.J.; Diaz, J.V.; Basu, C.; Diaz, A.; Pope, D.; Smith, K.R.; Smith-Sivertsen, T.; Bruce, N.; Solomon, C.; McCracken, J.; et al. Effects of woodsmoke exposure on airway inflammation in rural guatemalan women. PLoS One 2014, 9, doi:10.1371/journal.pone.0088455. eCollection 2014.

22. Zhou, Y.; Zou, Y.; Li, X.; Chen, S.; Zhao, Z.; He, F.; Zou, W.; Luo, Q.; Li, W.; Pan, Y.; et al. Lung function and incidence of chronic obstructive pulmonary disease after improved cooking fuels and kitchen ventilation: A 9-year prospective cohort study. PLoS Med. 2014, 11, doi:10.1371/ journal.pmed.1001621. eCollection 2014.

23. Li, Z.; Sjodin, A.; Romanoff, L.C.; Horton, K.; Fitzgerald, C.L.; Eppler, A.; Aguilar-Villalobos, M.; Naeher, L.P. Evaluation of exposure reduction to indoor air pollution in stove intervention projects in peru by urinary biomonitoring of polycyclic aromatic hydrocarbon metabolites. Environ. Int. 2011, 37, 1157-1163.

24. Pennise, D.; Brant, S.; Agbeve, S.M.; Quaye, W.; Mengesha, F.; Tadele, W.; Wofchuck, T. Indoor air quality impacts of an improved wood stove in ghana and an ethanol stove in ethiopia. Energy Sustain. Dev. 2009, 13, 71-76.

25. Sota, C.D.L.; Lumbreras, J.; Mazorra, J.; Narros, A.; Fernández, L.; Borge, R. Effectiveness of improved cookstoves to reduce indoor air pollution in developing countries. The case of the cassamance natural subregion, western Africa. J. Geosci. Environ. Protect. 2014, 2, 1-5.

26. McCracken, J.; Smith, K.R.; Stone, P.; Diaz, A.; Arana, B.; Schwartz, J. Intervention to lower household wood smoke exposure in guatemala reduces st-segment depression on electrocardiograms. Environ. Health Perspect. 2011, 119, 1562-1568.

27. McCracken, J.P.; Smith, K.R.; Diaz, A.; Mittleman, M.A.; Schwartz, J. Chimney stove intervention to reduce long-term wood smoke exposure lowers blood pressure among guatemalan women. Environ. Health Perspect. 2007, 115, 996-1001.

28. Thompson, L.M.; Bruce, N.; Eskenazi, B.; Diaz, A.; Pope, D.; Smith, K.R. Impact of reduced maternal exposures to wood smoke from an introduced chimney stove on newborn birth weight in rural guatemala. Environ. Health Perspect. 2011, 119, 1489-1494.

29. Clark, M.L.; Peel, J.L.; Balakrishnan, K.; Breysse, P.N.; Chillrud, S.N.; Naeher, L.P.; Rodes, C.E.; Vette, A.F.; Balbus, J.M. Health and household air pollution from solid fuel use: The need for improved exposure assessment. Environ. Health Perspect. 2013, 121, 1120-1128.

30. Mukhopadhyay, R.; Sambandam, S.; Pillarisetti, A.; Jack, D.; Mukhopadhyay, K.; Balakrishnan, K.; Vaswani, M.; Bates, M.N.; Kinney, P.L.; Arora, N.; et al. Cooking practices, air quality, and the acceptability of advanced cookstoves in haryana, India: An exploratory study to inform large-scale interventions. Glob. Health Action 2012, 5, 1-13. 
31. Jetter, J.J.; Kariher, P. Solid-fuel household cook stoves: Characterization of performance and emissions. Biomass Bioenergy 2009, 33, 294-305.

(C) 2015 by the authors; licensee MDPI, Basel, Switzerland. This article is an open access article distributed under the terms and conditions of the Creative Commons Attribution license (http://creativecommons.org/licenses/by/4.0/). 